\title{
Circulating S100B and Adiponectin in Children Who Underwent Open Heart Surgery and Cardiopulmonary Bypass
}

\author{
Alessandro Varrica, ${ }^{1}$ Angela Satriano, ${ }^{1}$ Alessandro Frigiola, ${ }^{1}$ Alessandro Giamberti, ${ }^{1}$ \\ Guido Tettamanti, ${ }^{1}$ Luigi Anastasia, ${ }^{1}$ Erika Conforti, ${ }^{1}$ Antonio D. W. Gavilanes, ${ }^{2}$ \\ Luc J. Zimmermann, ${ }^{2}$ Hans J. S. Vles, ${ }^{2}$ Giovanni Li Volti, ${ }^{3}$ and Diego Gazzolo ${ }^{4}$ \\ ${ }^{1}$ Department of Pediatric Cardiac Surgery IRCCS San Donato Milanese Hospital, Via Morandi 30, 20097 San Donato Milanese, Italy \\ ${ }^{2}$ Department of Pediatrics, Neonatology and Child Neurology, Maastricht University, P. Debyelaan 25, \\ 5800 Maastricht, Netherlands \\ ${ }^{3}$ Department of Drug Sciences, Section of Biochemistry, University of Catania, Viale A. Doria 6, 95125 Catania, Italy \\ ${ }^{4}$ Department of Maternal Fetal and Neonatal Medicine, C. Arrigo Children's Hospital, Spalto Marengo 46, 15100 Alessandria, Italy
}

Correspondence should be addressed to Alessandro Varrica; a.varrica@virgilio.it

Received 26 June 2014; Accepted 26 October 2014

Academic Editor: Giovanni Scapagnini

Copyright (c) 2015 Alessandro Varrica et al. This is an open access article distributed under the Creative Commons Attribution License, which permits unrestricted use, distribution, and reproduction in any medium, provided the original work is properly cited.

Background. S100B protein, previously proposed as a consolidated marker of brain damage in congenital heart disease (CHD) newborns who underwent cardiac surgery and cardiopulmonary bypass (CPB), has been progressively abandoned due to S100B CNS extra-source such as adipose tissue. The present study investigated CHD newborns, if adipose tissue contributes significantly to S100B serum levels. Methods. We conducted a prospective study in $26 \mathrm{CHD}$ infants, without preexisting neurological disorders, who underwent cardiac surgery and $\mathrm{CPB}$ in whom blood samples for $\mathrm{S100B}$ and adiponectin (ADN) measurement were drawn at five perioperative time-points. Results. S100B showed a significant increase from hospital admission up to $24 \mathrm{~h}$ after procedure reaching its maximum peak $(P<0.01)$ during $\mathrm{CPB}$ and at the end of the surgical procedure. Moreover, ADN showed a flat pattern and no significant differences $(P>0.05)$ have been found all along perioperative monitoring. ADN/S100B ratio pattern was identical to S100B alone with the higher peak at the end of CPB and remained higher up to $24 \mathrm{~h}$ from surgery. Conclusions. The present study provides evidence that, in CHD infants, S100B protein is not affected by an extra-source adipose tissue release as suggested by no changes in circulating $\mathrm{ADN}$ concentrations.

\section{Introduction}

Advances in cardiothoracic surgical and anesthetic techniques, including cardiopulmonary bypass (CPB), have substantially decreased mortality, expanding the horizon to address functional neurologic and cardiac outcomes in longterm survivors [1]. Acute neurocardiac morbidities in congenital heart disease (CHD) infants are well described and interest in the functional status of survivors now stretches beyond the newborn period to childhood, adolescence, and adulthood [2]. Newborn heart surgery represents a period of planned and deliberate hypoxia-ischemia (HI) injury, which is the price to pay in the treatment or palliation of CHD. To date, the possibility of detecting infants at risk for mortality and morbidity is limited since clinical, laboratory, and standard monitoring procedures may be silent or unreliable [3]. Thus, a practical and sensitive marker able to offer physicians a useful tool for clinical is therefore eagerly awaited.

In the last decade a brain constituent, namely, S100B protein, has been proposed as a well-established marker of brain damage and death [4-10], since elevated S100B concentrations in different biological fluids have been found in adults, infants, and fetuses at risk for brain damage [415]. S100B is an acidic calcium-modulated protein of low molecular weight, first identified by Moore as a protein 
fraction detectable in the central nervous system (CNS) in glial and Schwann cells and in specific neuronal subpopulations [16]. With regard to CHD infants who underwent cardiac surgery and $\mathrm{CPB}, \mathrm{S} 100 \mathrm{~B}$ has been shown to be increased in the perioperative period $[17,18]$, to correlate with different $\mathrm{CPB}$ phases [19] and with increased cerebrovascular resistance and brain damage [20]. However, protein's assessment in CHD infants for CPB monitoring has been progressively abandoned on the basis of S100B extra CNS site of concentrations including adipose tissue [21]. The issue is still controversial and matter of debate. From one side, a contamination originating by mediastinal tissues on S100B releasing into systemic circulation has been suggested [2225]. From the other side, it has been shown that extracranial sources of S100B do not affect serum levels and protein's diagnostic value in neurological diseases in intact subjects [26]. In this setting, data in nonintact patients such as without traumatic brain or bodily injury from accident or surgery are still lacking.

Therefore, the objective of this current study was to determine, in $\mathrm{CHD}$ newborns, if adipose tissue sources contribute significantly to serum levels of S100B by means of the longitudinal measurement of adiponectin (ADN), the most abundant adipose-derived protein in humans [27] and S100B at different perioperative time-points.

\section{Materials and Methods}

2.1. Patients. From March 2010 to September 2011, we conducted an observational study in which 26 infants (15 males and 11 females) from 0 to 9 months of age (mean 30.4 months), without preexisting neurological disorders or other comorbidities, admitted to our referral centers for the correction of congenital heart defects (Table 1). Exclusion criteria included need for inotropic support or mechanical ventilation prior to surgery, recent cardiac arrest, and weight of less than $2 \mathrm{~kg}$.

Informed consent from parents was obtained before patient inclusion in the study, which was approved by the local human-investigation committee.

Blood samples were drawn at five predetermined timepoints in the preoperative period as follows: before the surgical procedure (time $0, T 0$ ); during the surgical procedure before CPB (time 1, T1); at the end of CPB (time 2, T2); at the end of the surgical procedure (time 3, T3); $24 \mathrm{~h}$ after the surgical procedure (time $4, T 4$ ). At these timepoints $\mathrm{ADN}$ levels and $\mathrm{ADN} / \mathrm{S} 100 \mathrm{~B}$ ratio were measured. Clinical parameters (peripheral temperature, nasopharyngeal temperature, pump flow rate, mean blood pressure, and arterial $\mathrm{pH}$ ) were recorded at all sample times for the purpose of monitoring the general pattern of the surgical procedure.

2.1.1. Anesthetic Technique. After premedication with midazolam $0.5 \mathrm{mg} / \mathrm{Kg}$ bw (rectal/intramuscular), induction was achieved with oxygen and 3\% sevofluorane administered via mask (single breath induction), followed by intravenous sufentanil 1 (g/Kg bw) and vecuronium $(0.15 \mathrm{mg} / \mathrm{Kg} \mathrm{bw})$. Maintenance was achieved with 3\% sevofluorane (except
TABLE 1: General characteristics and perioperative data in the infants admitted into the study. Data are given as mean \pm SD.

\begin{tabular}{lc}
\hline Parameters & \\
\hline Age (months) & $41.6 \pm 30.4$ \\
Sex (male/female) & $15 / 11$ \\
Weight (Kg) & $11.5 \pm 4.7$ \\
Type of surgery & \\
$\quad$ Great artery transposition (no) & 4 \\
Ventricular septal defect (no) & 5 \\
Total anomalous pulmonary vein connection (no) & 4 \\
Tetralogy of fallot (no) & 2 \\
Double outlet right ventricle (no) & 3 \\
Complete A-V canal defect (no) & 2 \\
Atrial septal defect (no) & 6 \\
CPB duration (min) (no) & $89.9 \pm 43.4$ \\
Cross clamp duration (min) & $45.1 \pm 32.2$ \\
Temperature in CPB ( $\left.{ }^{\circ} \mathrm{C}\right)$ median & $31.8 \pm 3.5$ \\
MUF (no) & 20 \\
\hline
\end{tabular}

AV: atrioventricular; CPB: cardiopulmonary bypass; and MUF: modified ultrafiltration.

during $\mathrm{CPB}$ ) and with additional doses of sufentanil $(0.5 \mathrm{~g} / \mathrm{Kg} \mathrm{bw})$ and vecuronium $(0.1 \mathrm{mg} / \mathrm{Kg} \mathrm{bw})$ every $30-$ $40 \mathrm{~min}$. During CPB, in the absence of sevofluorane, additional midazolam at $0.2 \mathrm{mg} / \mathrm{Kg}$ bw dosage was given. Sufentanil infusion at $0.25 \mathrm{~g} / \mathrm{Kg}$ bw was continued in the intensive care unit for sedation.

2.1.2. Cardiopulmonary Bypass Management. CPB was established after systemic heparinization $(3 \mathrm{mg} / \mathrm{Kg} \mathrm{bw})$ by standard single stage aortic and bicaval cannulation and was maintained via nonpulsatile pump flow with a membrane oxygenator (Dideco Laboratories, Modena, Italy). Flow velocity was kept at $120-150 \mathrm{~mL} / \mathrm{Kg}$ bw and mean arterial blood pressure at $45 \mathrm{mmHg}$; hypothermia was attained by core and surface cooling. Mean CPB duration time was $90 \pm$ 43 min; mean rewarming time was $15 \pm 8$ min (mean \pm SD), calculated from the final temperature during hypothermic circulatory arrest to $36.5^{\circ} \mathrm{C}$. The minimum temperature reached was $27.2^{\circ} \mathrm{C}$. The pump priming solution was composed of electrolyte solutions (Normosol-R 250 to $650 \mathrm{~mL}$, Abbott Hospital Products, Abbott Park, IL, USA or PlasmaLyte A, Travenol Laboratories, Inc., Deerfield, IL, USA), albumin (25\%), heparin 1000 to 5000 units in the total solution, sodium bicarbonate $(25-30 \mathrm{mEq} / \mathrm{L})$, and packed red blood cells or fresh frozen plasma. A standard circuit prime total volume was used, according to body-weight varying from $400 \mathrm{~mL}$ (bw $<4.5 \mathrm{Kg}$ ) to $600 \mathrm{~mL}$ (bw $>4.5 \mathrm{Kg}$ and bw $<$ $7.5 \mathrm{~kg}$ ) and to $700 \mathrm{~mL}$ (bw $>7.7 \mathrm{~kg}$ ). Packed red blood cells (200 to $500 \mathrm{~mL}$ ) were transfused as necessary to maintain a hematocrit level above $30 \%$ during CPB [26]. Protamine ( $1 \mathrm{mg}$ for each $\mathrm{mg}$ of heparin) was administered at the end of CPB.

The $\alpha$-stat regimen was used, and the $\mathrm{PaCO}_{2}$ was maintained between 35 and $40 \mathrm{mmHg}$, without mathematical 
correction for the effects of the temperature, by varying the membrane oxygenator gas flow.

2.1.3. Adiponectin Measurement. Serum ADN concentrations were determined by an enzyme-linked immunosorbent assay (Human Adiponectin ELISA, EZHADP-61 K; Linco Research). Sensitivity limit for this assay is $0.78 \mathrm{ng} / \mathrm{mL}$ for Human Adiponectin ( $20 \mu \mathrm{L}$ sample size). The appropriate range of the assay is 1.56 to $200 \mathrm{ng} / \mathrm{mL}$ Human Adiponectin (20 $\mu \mathrm{L}$ sample size). The results were evaluated according to $\mathrm{ng} / \mathrm{mL}$.

2.1.4. S100B Measurement. Samples for S100B measurements at the seven monitoring time-points were drawn from a catheter inserted in the jugular vein. Heparin-treated blood samples were immediately centrifuged at $900 \mathrm{~g}$ for $10 \mathrm{~min}$ and the supernatants were stored at $-70^{\circ} \mathrm{C}$ before measurement. The S100B protein concentration was measured in all samples using a commercially available two-site immunoradiometric assay kit (Sangtec 100; AD Sangtec Medical, Bromma, Sweden) specific to the $\beta$-subunit of the protein, which is known to be present mostly (80-96\%) in the human brain [28]. Each measurement was performed in duplicate and the mean values are reported. The limit of sensitivity of the assay was $0.02 \mu \mathrm{g} / \mathrm{L}$. The precision (CV) was $<10 \%$.

2.1.5. Neurological Follow-Up. Neurological development was assessed by physical examination, preoperatively and on the 7th postoperative day, based on Amiel-Tison's criteria [29]. In particular, resistance against passive movements, visual pursuit, reaching and grasping, and responses to visual and acoustic stimuli were tested by the same examiner, who did not know of the subjects' presurgical condition.

2.2. Statistical Analysis. ADN and S100B plasma concentrations are expressed as median and 5-95\% coefficient intervals (CI). Comparisons at the different monitoring timepoints were analyzed by Kruskal-Wallis one-way ANOVA. Linear regression analysis was used for correlation between $\mathrm{ADN}$ and $\mathrm{S} 100 \mathrm{~B}$ and various parameters $\mathrm{CPB}$, cooling, and rewarming duration; body core temperature; arterial blood $\mathrm{pH}$, arterial oxygen and carbon dioxide partial pressures, and base excess; and mean arterial blood pressure and heart rate). Statistical significance was set at $P<0.05$.

\section{Results}

In Table 1 patients' characteristics are reported. Clinical, laboratory, and standard monitoring parameters recorded at the predetermined time-points remained within the reference limits and therefore were not different $(P>0.05$; for all $)$ in all infants. Intraoperative parameters such as $\mathrm{CPB}$, crossclamping, cooling, and rewarming durations were within reference ranges and no perioperative complications have been shown. No complications in the postoperative period have been reported and no overt neurological disease was detected at discharge from hospital.

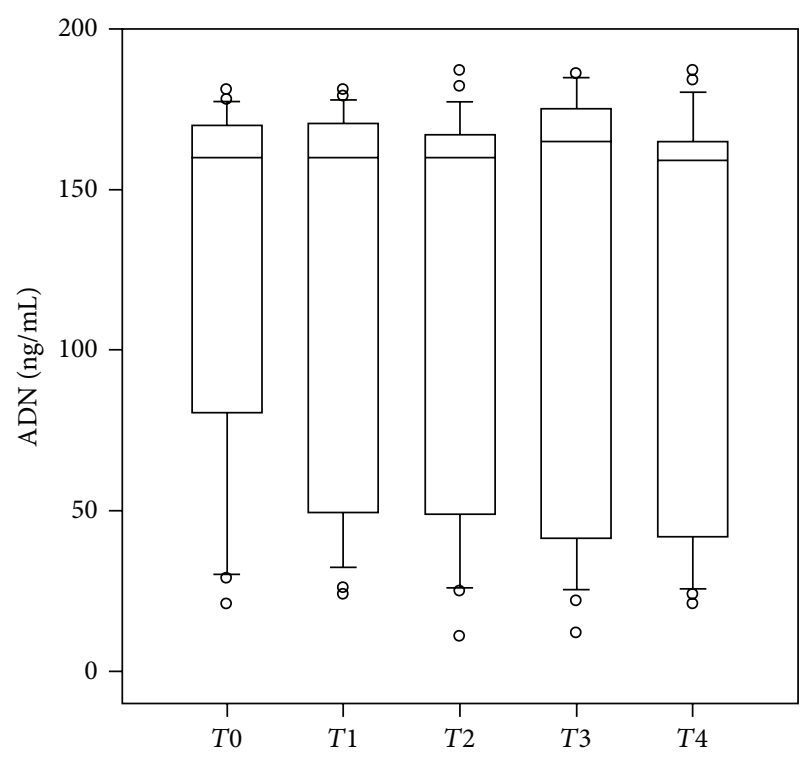

FIGURE 1: Adiponectin (ADN) (ng/mL) blood concentrations expressed as median and coefficient intervals $\left(\mathrm{CI}_{5-95 \%}\right)$ at different monitoring time-points (before the surgical procedure $(\mathrm{T} 0)$; during the surgical procedure after sternotomy before CPB (T1); at the end $\mathrm{CPB}(T 2)$; at the end of the surgical procedure (T3); and at $24 \mathrm{~h}$ after the surgical procedure (time $4, T 4)$ ).

ADN was measurable in all samples collected. ADN pattern at different monitoring time-points showed a flat trend and therefore no significant differences $(P>0.05$, for all) have been found all along perioperative monitoring up to $24 \mathrm{~h}$ from surgery ( $T 0-T 4)$ (Figure 1 ).

S100B was measurable in all samples collected. S100B pattern at different monitoring time-points was characterized by a protein's significant increase $(P<0.01$, for all), reaching its highest peak at the end of $\mathrm{CPB}$ and remaining stable up to $24 \mathrm{~h}$ from surgery (Figure 2(a)).

Linear regression analysis showed no significant correlations $(P>0.05$, for all $)$ between $\mathrm{ADN}$ and $\mathrm{S100 \textrm {B }}$ at all monitoring time-points (T0-T4) and between ADN and CPB $(r=0.08 ; P=0.73)$ and cross clamp $(r=0.05 ; P=$ 0.82 ) durations. Conversely, S100B significantly correlated with $\mathrm{CPB}(r=0.53 ; P=0.003)$ and at cross clamp $(r=0.65$; $P<0.01)$ durations.

ADN/S100B ratio pattern was characterized by a significant increase $(P<0.01)$ from $T 0$ to $T 3$ reaching its dip at $T 2$ and returning at $T 4$ at preoperative levels. No significant correlations $(P>0.05$, for all) between $\mathrm{ADN} / \mathrm{S} 100 \mathrm{~B}$ ratio and CPB $(r=0.12 ; P=0.56)$ and cross clamp $(R=0.19$; $P=0.35$ ) duration have been found (Figure 2(b)).

\section{Discussion}

Despite recent advances in cardiac surgery and $\mathrm{CPB}$ management, the possibility of detecting infants at risk for neonatal mortality and morbidity is still faraway due to limitations in the standard monitoring procedures currently performed $[1,2]$. In this setting, brain biomarkers previously suggested 


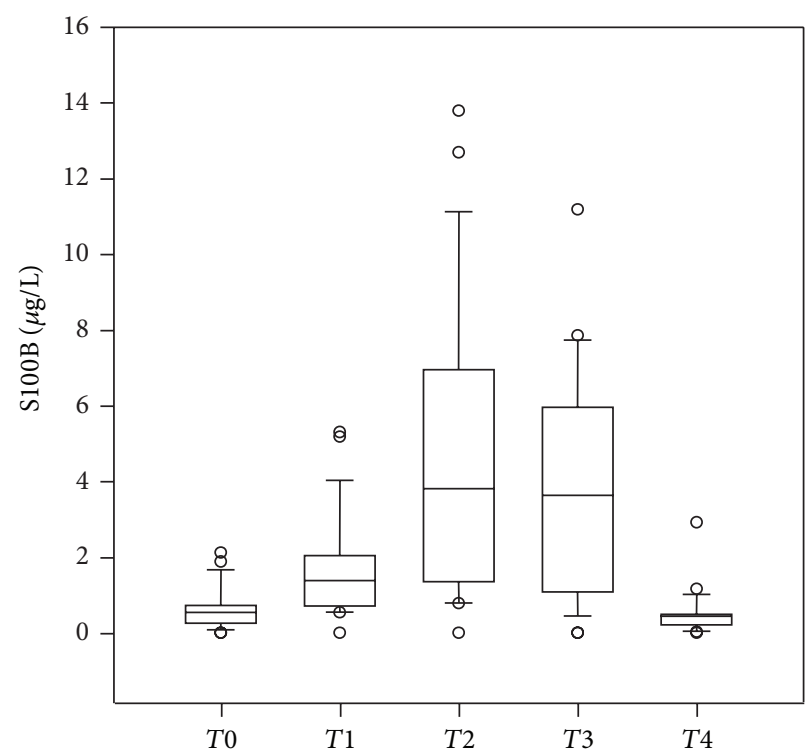

(a)

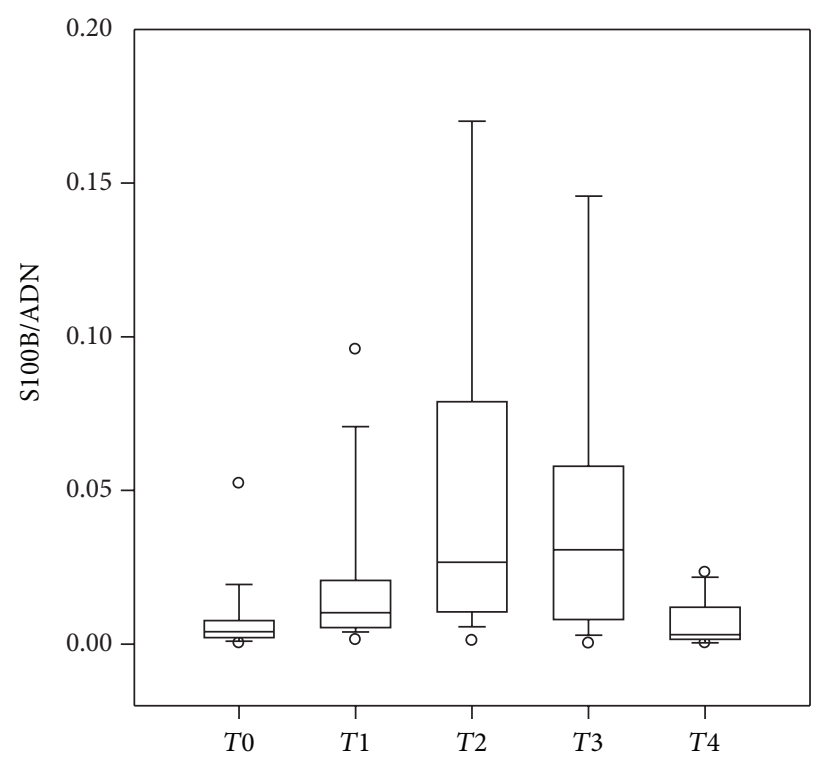

(b)

FIGURE 2: (a) S100B $(\mu \mathrm{g} / \mathrm{L})$ blood concentrations expressed as median and coefficient intervals $\left(\mathrm{CI}_{5-95 \%}\right)$ at different monitoring time-points (before the surgical procedure ( $T 0)$; during the surgical procedure after sternotomy before $\mathrm{CPB}(\mathrm{T} 1)$; at the end $\mathrm{CPB}(\mathrm{T2})$; at the end of the surgical procedure (T3) and at $24 \mathrm{~h}$ after the surgical procedure (time $4, T 4)$ ). ${ }^{*} \mathrm{P}<0.01$ versus $T 0$. (b) S100B ( $\mu \mathrm{g} / \mathrm{L}$ ) and adiponectin (ADN) $(\mathrm{ng} / \mathrm{mL})$ blood concentrations expressed as median and coefficient intervals $\left(\mathrm{CI}_{5-95 \%}\right)$ at different monitoring time-points (before the surgical procedure (T0); during the surgical procedure after sternotomy before $\mathrm{CPB}(T 1)$; at the end $\mathrm{CPB}(\mathrm{T} 2)$; at the end of the surgical procedure (T3); and at $24 \mathrm{~h}$ after the surgical procedure (time $4, T 4)$ ). ${ }^{*} P<0.01$ versus $T 0$.

as promising tools disappointed expectations and, to date, a trustable biomarker of brain damage in the perioperative period is still eagerly awaited. This holds for S100B protein, first reported as a useful tool and later on abandoned for brain monitoring of CHD adults and children [18-21]. The explanations are still controversial and debated although the main resides in a contamination by protein' extrasources such as adipose tissue [22-25].

The present study provides evidence that, in CHD infants, S100B protein is not affected by an extrasource adipose tissue release as suggested by no changes in circulating ADN concentrations. Furthermore, the ADN/S100B ratio pattern was superimposable to $\mathrm{S} 100 \mathrm{~B}$ alone all along the perioperative period.

The finding of $\mathrm{ADN}$ trend in the perioperative period is not surprising and fits, in part, previous observations in pediatric patients where decreased ADN levels have been reported [27]. The discrepancies are several and reside in the number, timing, and the length of the monitoring time-points and in the different $\mathrm{CPB}$ management (mild versus moderate hypothermia). In this setting, hypothermia is known to activate an exaggerated release of proinflammatory cytokines and of endogenous cortisol that may be responsible of decreased ADN transcription and blood levels [27, 30, 31]. Anyway, further investigations comparing $\mathrm{ADN}$ pattern under different CPB management such as mild versus moderate/deep hypothermia are so justified.

The finding of increased S100B levels and flat ADN/S100B ratio enforces the debating issue on the protein' pros and cons as brain stress/damage marker in CHD patients. From one hand, the absence of any interference in circulating S100B in the perioperative period is in agreement with previous observations, both in adults and children, reporting no compromise on the diagnostic value of S100B in neurological diseases in intact subjects (without traumatic brain or bodily injury from accident or surgery) [26]. These findings are also consistent with the usefulness of the protein in brain monitoring of CHD infants [18-20]. On the other hand, the discrepancy with previous observations warrants further consideration in terms of contamination following invasive procedures during $\mathrm{CPB}$. This refers to $\mathrm{CPB}$ standard procedures, known to increase mediastinum release of the protein, as pericardial suction blood re-/autotransfusion, zerobalanced ultra-filtration, and pericardial blood processing with cell-saving devices [22-25, 32-34]. The high S100B levels at the site of reinfusion is per se of limited relevance because of the known mediastinum site of concentration of the protein. In fact, once S100B was measured in systemic circulation, after reinfusion procedures, its concentration did not appear to be affected by mediastinum source [35]. The main explanations reside in lowest S100B extrasources' concentrations when compared with the total amount of the protein in the CNS [36]. Although, there are no observations in pediatric and postnatal periods in whom protein distribution in CNS and other tissues can differ or not from adults [37], in the latter (estimated for a $70 \mathrm{Kg}$ man) the absolute amount of S100B in the tissue (calculated in micrograms) showed the highest protein's concentration in brain (538.000 $\mu \mathrm{g}$ : 90.9\%) followed by muscles (42.000 $\mu \mathrm{g}: 7.1 \%)$, adipose tissue (10.500 $\mu \mathrm{g}: 1.77 \%)$, heart (1.000 $\mu \mathrm{g}: 0.2 \%)$, 
and liver (200 $\mu \mathrm{g}: 0.03 \%)$ [36]. Taken together, the possibility that adipose tissue could constitute a significant source of contamination affecting S100B diagnostic value seems to be fairly remote.

Among different S100B sites of contamination cardiac tissue extrasource deserves further consideration [36]. In particular (i) in rat model of myocardial infarction it has been shown that S100B may play a dual role in cardiomyocytes survival or death (i.e., necrosis and apoptosis) through a RAGE-dependent mechanism, and (ii) S100B, once released from damaged myocytes, with consequent leakage of the protein into the systemic circulation, is approximately 1000 -fold less than the amount of protein required to induce apoptosis [38]. Indeed, local high S100B concentration was detected only at the site of myocardial infarction and, finally, (iii) in humans, cardiac tissue contamination on S100B has been justified by a correlation between troponin I and S100B [23] although a hypoxia mediated effect could be reasonably the main explanation of the increase in circulating biomarkers' levels $[3,4]$. Altogether, bearing in mind the extremely low protein' concentrations in cardiac tissue the present findings suggest that the possibility of a cardiac tissue extrasource contamination on circulating S100B levels argue against this hypothesis. Conversely, it is reasonable to suppose that the upregulation of S100B protein is a consequence of hypoxia itself, instead of dead cells belonging to the necrosis/apoptosis area. To this regard, it has been demonstrated both in humans and in sheep model that acute hypoxemia is able to induce a significant increase in S100B release within 15 minute form insult in absence of any CNS damage [39]. This is of great relative interest to this contest because, as shown in our series, it is possible to argue that $\mathrm{H}-\mathrm{I}$ insult occurring during $\mathrm{CPB}$ phase may trigger protein's release due to "multiorgan" stress of whom CNS constitutes the majority of the total protein's amount $[3,4,36]$. In this regard, further studies aimed at investigating potential confounding factors such as S100A1 and RAGE and the S100A1B dimer interactions in the cascade of events leading to cell death and apoptosis are still needed.

In conclusion, our results showing, in nonintact patients, that $\mathrm{S100B}$ protein is not affected by an extrasource adipose tissue release during the perioperative period open up further studies, in wider populations, aimed at confirming protein's role of early marker of hypoxia and CNS stress/damage in CHD children.

\section{List of Abbreviations}

CPB: Cardiopulmonary bypass

CHD: Congenital heart diseases

CNS: Central nervous system

ADN: Adiponectin

SD: Standard deviation

CI: Coefficient intervals.

\section{Conflict of Interests}

The authors declare that there is no conflict of interests regarding the publication of this paper.

\section{Acknowledgments}

This study is part of the I.O. Ph.D. International Program, under the auspices of the Italian Society of Neonatology and of the Neonatal Clinical Biochemistry Research Group, and was partially supported by grants to Diego Gazzolo from I Colori della Vita Foundation, Italy.

\section{References}

[1] A. Kansy, Z. Tobota, P. Maruszewski, and B. Maruszewski, "Analysis of 14,843 neonatal congenital heart surgical procedures in the European association for cardiothoracic surgery congenital database," Annals of Thoracic Surgery, vol. 89, no. 4, pp. 1255-1259, 2010.

[2] D. C. Bellinger, R. A. Jonas, L. A. Rappaport et al., "Developmental and neurologic status of children after heart surgery with hypothermic circulatory arrest or low-flow cardiopulmonary bypass," The England Journal of Medicine, vol. 332, no. 9, pp. 549-555, 1995.

[3] R. Donato, B. R. Cannon, G. Sorci et al., "Functions of S100 proteins," Current Molecular Medicine, vol. 13, no. 1, pp. 24-57, 2013.

[4] F. Michetti, V. Corvino, M. C. Geloso et al., "The S100B protein in biological fluids: more than a lifelong biomarker of brain distress," Journal of Neurochemistry, vol. 120, no. 5, pp. 644-659, 2012.

[5] B. W. Schäfer and C. W. Heizmann, "The S100 family of EF-hand calcium-binding proteins: functions and pathology," Trends in Biochemical Sciences, vol. 21, no. 4, pp. 134-140, 1996.

[6] G. Fanò, S. Biocca, S. Fulle, M. A. Mariggio, S. Belia, and P. Calissano, "The S-100: a protein family in search of a function," Progress in Neurobiology, vol. 46, no. 1, pp. 71-82, 1995.

[7] C. W. Heizmann, "Ca2+-binding S100 proteins in the central nervous system," Neurochemical Research, vol. 24, no. 9, pp. 1097-1100, 1999.

[8] P. Florio, F. Michetti, M. Bruschettini et al., "Amniotic fluid S100B protein in mid-gestation and intrauterine fetal death," The Lancet, vol. 364, no. 9430, pp. 270-272, 2004.

[9] D. Gazzolo, A. Frigiola, M. Bashir et al., "Diagnostic accuracy of S100B urinary testing at birth in full-term asphyxiated newborns to predict neonatal death," PLoS ONE, vol. 4, no. 2, Article ID e4298, 2009.

[10] D. Gazzolo, P. Florio, S. Ciotti et al., "S100B protein in urine of preterm newborns with ominous outcome," Pediatric Research, vol. 58, no. 6, pp. 1170-1174, 2005.

[11] D. Gazzolo, E. Marinoni, R. di Iorio, M. Lituania, P. L. Bruschettini, and F. Michetti, "Circulating $S 100 \beta$ protein is increased in intrauterine growth-retarded fetuses," Pediatric Research, vol. 51, no. 2, pp. 215-219, 2002.

[12] D. Gazzolo, D. Grutzfeld, F. Michetti et al., "Increased S100B in cerebrospinal fluid of infants with bacterial meningitis: relationship to brain damage and routine cerebrospinal fluid findings," Clinical Chemistry, vol. 50, no. 5, pp. 941-944, 2004.

[13] D. Gazzolo, P. Vinesi, M. Bartocci et al., "Elevated S100 blood level as an early indicator of intraventricular hemorrhage in preterm infants: Correlation with cerebral Doppler velocimetry," Journal of the Neurological Sciences, vol. 170, no. 1, pp. 3235, 1999.

[14] D. Gazzolo, P. Florio, S. Ciotti et al., "S100B protein in urine of preterm newborns with ominous outcome," Pediatric Research, vol. 58, no. 6, pp. 1170-1174, 2005. 
[15] P. Florio, E. Marinoni, R. di Iorio et al., "Urinary S100B protein concentrations are increased in intrauterine growth-retarded newborns," Pediatrics, vol. 118, no. 3, pp. e747-e754, 2006.

[16] B. W. Moore, "A soluble protein characteristic of the nervous system," Biochemical and Biophysical Research Communications, vol. 19, no. 6, pp. 739-744, 1965.

[17] S. Westaby, P. Johnsson, A. J. Parry et al., "Serum S100 protein: a potential marker for cerebral events during cardiopulmonary bypass," Annals of Thoracic Surgery, vol. 61, no. 1, pp. 88-92, 1996.

[18] P. M. Bokesch, E. Appachi, M. Cavaglia, E. Mossad, and R. B. B. Mee, "A glial-derived protein, S100B, in neonates and infants with congenital heart disease: evidence for preexisting neurologic injury," Anesthesia and Analgesia, vol. 95, no. 4, pp. 889-892, 2002.

[19] D. Gazzolo, P. Vinesi, M. C. Geloso et al., "S100 blood concentrations in children subjected to cardiopulmonary by-pass," Clinical Chemistry, vol. 44, no. 5, pp. 1058-1060, 1998.

[20] D. Gazzolo, P. Masetti, M. Kornacka, R. Abella, P. Bruschettini, and F. Michetti, "Phentolamine administration increases blood S100B protein levels in pediatric open-heart surgery patients," Acta Paediatrica, vol. 92, no. 12, pp. 1427-1432, 2003.

[21] J. Vaage and R. Anderson, "Biochemical markers of neurologic injury in cardiac surgery: the rise and fall of S100 $\beta$," Journal of Thoracic and Cardiovascular Surgery, vol. 122, no. 5, pp. 853-855, 2001.

[22] J. Babin-Ebell, P. Roth, J. Reese, M. Bechtel, and A. Mortasawi, "Serum S100B levels in patients after cardiac surgery: possible sources of contamination," Thoracic and Cardiovascular Surgeon, vol. 55, no. 3, pp. 168-172, 2007.

[23] S. A. Snyder-Ramos, T. Gruhlke, H. Bauer et al., "Cerebral and extracerebral release of protein S100B in cardiac surgical patients," Anaesthesia, vol. 59, no. 4, pp. 344-349, 2004.

[24] H. Jönsson, P. Johnsson, M. Bäckström, C. Alling, C. DautovicBergh, and S. Blomquist, "Controversial significance of early S100B levels after cardiac surgery," BMC Neurology, vol. 4, article 24, 2004.

[25] S. Svenmarker and K. G. Engström, "The inflammatory response to recycled pericardial suction blood and the influence of cell-saving," Scandinavian Cardiovascular Journal, vol. 37, no. 3, pp. 158-164, 2003.

[26] N. Pham, V. Fazio, L. Cucullo et al., "Extracranial sources of S100B do not affect serum levels," PLoS ONE, vol. 5, no. 9, Article ID e12691, 2010.

[27] A. Thaler, H. Kanety, T. Avni et al., "Postoperative adiponectin levels in pediatric patients undergoing open heart surgery," BioMed Research International, vol. 2013, Article ID 408680, 7 pages, 2013.

[28] R. Jensen, D. R. Marshak, C. Anderson, T. J. Lukas, and D. M. Watterson, "Characterization of human brain S100 protein fraction: amino acid sequence of $\$ 100 \beta$," Journal of Neurochemistry, vol. 45, no. 3, pp. 700-705, 1985.

[29] C. Amiel-Tison, "Neurological evaluation of the maturity of newborn infants," Archives of Disease in Childhood, vol. 43, no. 227, pp. 89-93, 1968.

[30] H. T. F. de Mendonça-Filho, K. C. Pereira, M. Fontes et al., "Circulating inflammatory mediators and organ dysfunction after cardiovascular surgery with cardiopulmonary bypass: a prospective observational study," Critical Care, vol. 10, no. 2, article R46, 2006.
[31] H. Tilg and A. R. Moschen, "Inflammatory mechanisms in the regulation of insulin resistance," Molecular Medicine, vol. 14, no. 3-4, pp. 222-231, 2008.

[32] M. Carrier, A. Denault, J. Lavoie, and L. P. Perrault, "Randomized controlled trial of pericardial blood processing with a cell-saving device on neurologic markers in elderly patients undergoing coronary artery bypass graft surgery," Annals of Thoracic Surgery, vol. 82, no. 1, pp. 51-55, 2006.

[33] M. de Baar, J. C. Diephuis, K. G. M. Moons, J. Holtkamp, R. Hijman, and C. J. Kalkman, "The effect of zero-balanced ultrafiltration during cardiopulmonary bypass on S100b release and cognitive function," Perfusion, vol. 18, no. 1, pp. 9-14, 2003.

[34] M. Carrier, A. Denault, J. Lavoie, and L. P. Perrault, "Randomized controlled trial of pericardial blood processing with a cell-saving device on neurologic markers in elderly patients undergoing coronary artery bypass graft surgery," The Annals of Thoracic Surgery, vol. 82, no. 1, pp. 51-55, 2006.

[35] H. Jönsson, "S100B and cardiac surgery: possibilities and limitations," Restorative Neurology and Neuroscience, vol. 21, no. 3-4, pp. 151-157, 2003.

[36] H. Haimoto, S. Hosoda, and K. Kato, "Differential distribution of immunoreactive S100- $\alpha$ and S100- $\beta$ proteins in normal nonnervous human tissues," Laboratory Investigation, vol. 57, no. 5, pp. 489-498, 1987.

[37] E. Cacciari, S. Milani, A. Balsamo et al., "Italian cross-sectional growth charts for height, weight and BMI (2 to $20 \mathrm{yr}$ )," Journal of Endocrinological Investigation, vol. 29, no. 7, pp. 581-593, 2006.

[38] J. N. Tsoporis, S. Izhar, H. Leong-Poi, J.-F. Desjardins, H. J. Huttunen, and T. G. Parker, "S100B interaction with the receptor for advanced glycation end products (RAGE): a novel receptormediated mechanism for myocyte apoptosis postinfarction," Circulation Research, vol. 106, no. 1, pp. 93-101, 2010.

[39] D. A. Giussani, A. S. Thakor, R. Frulio, and D. Gazzolo, "Acute hypoxia increases $S 100 \beta$ protein in association with blood flow redistribution away from peripheral circulations in fetal sheep," Pediatric Research, vol. 58, no. 2, pp. 179-184, 2005. 

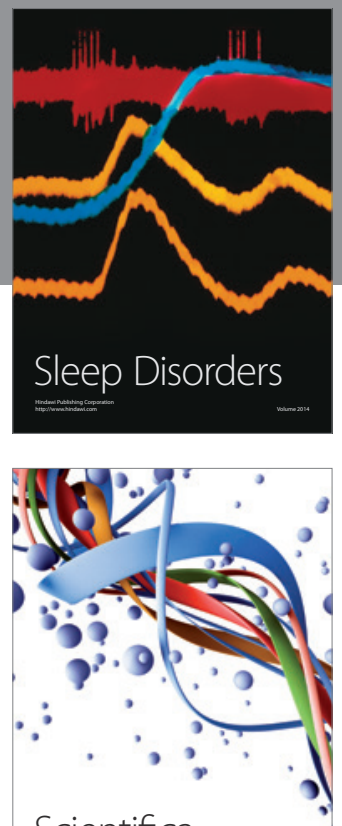

Scientifica
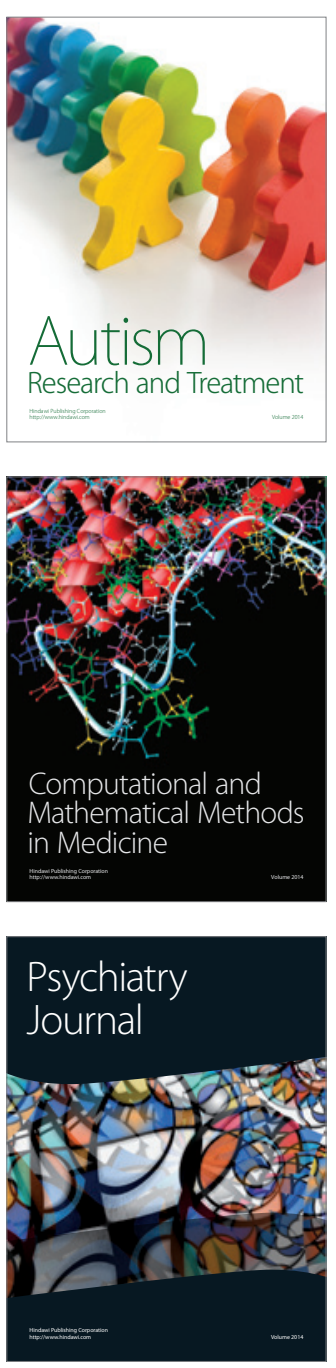
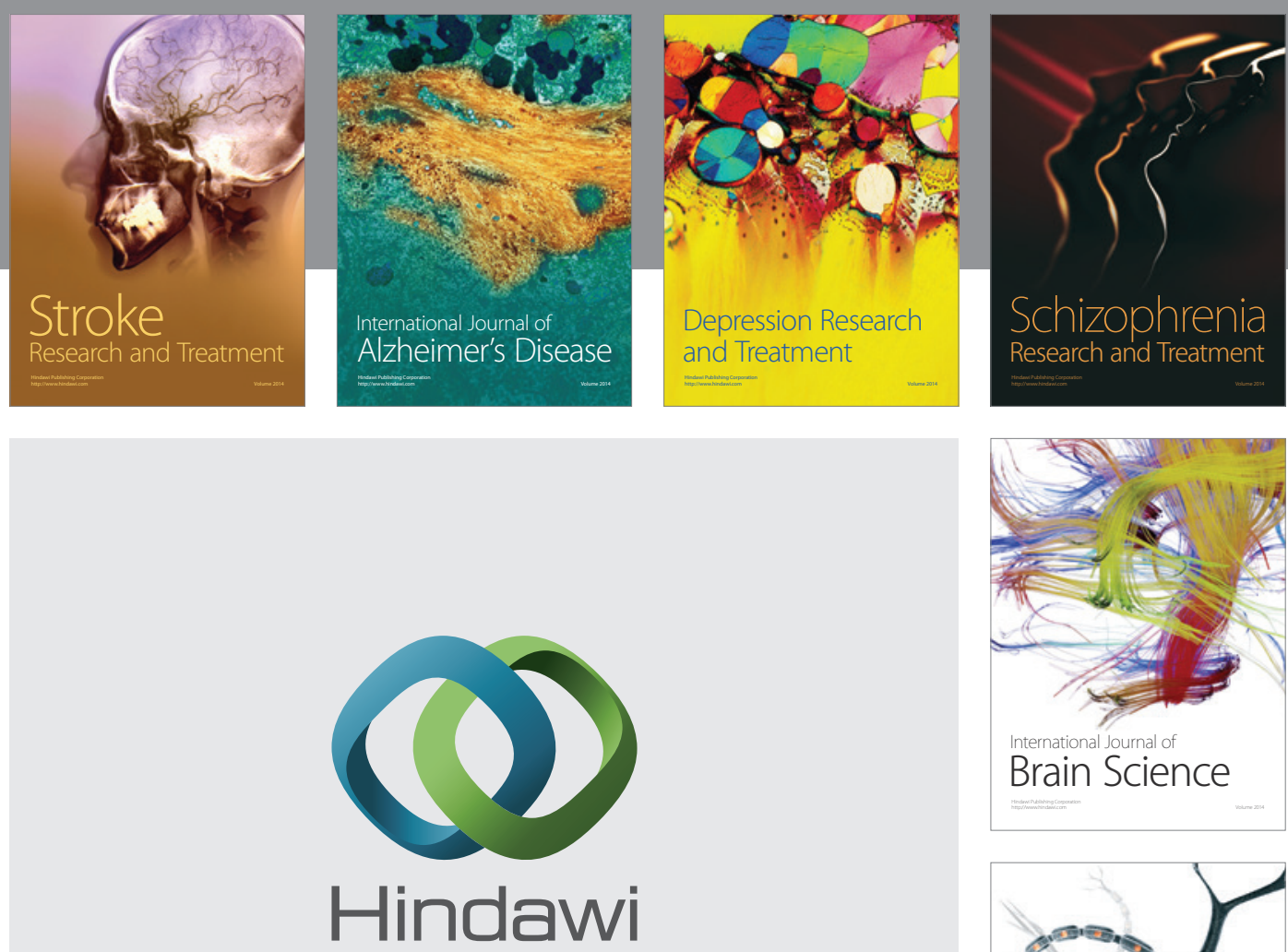

Submit your manuscripts at

http://www.hindawi.com
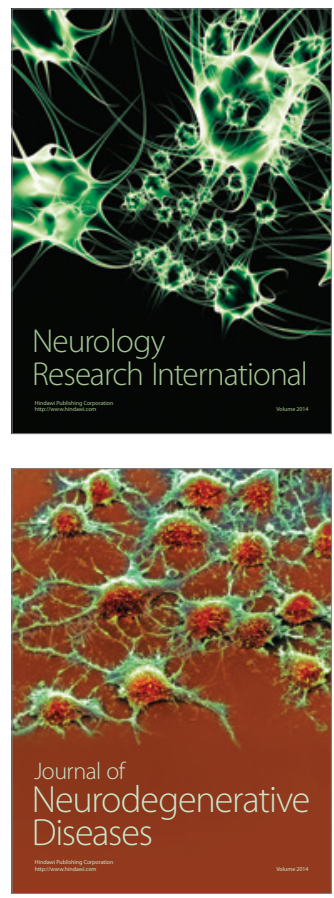

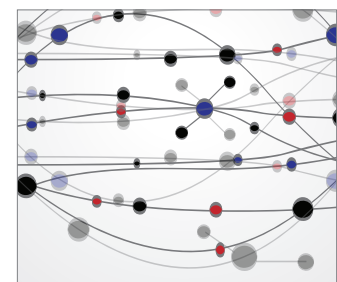

The Scientific World Journal
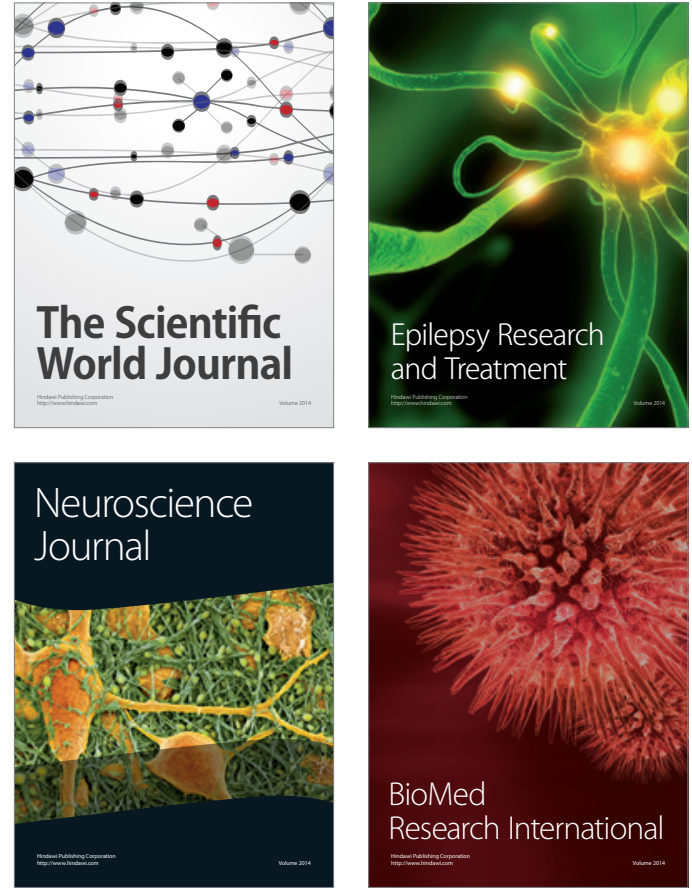

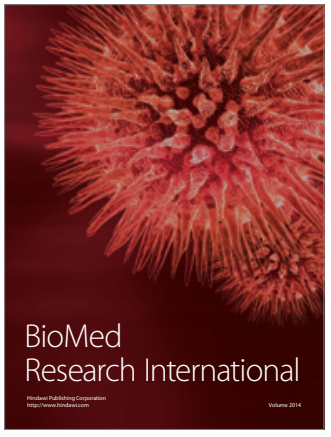

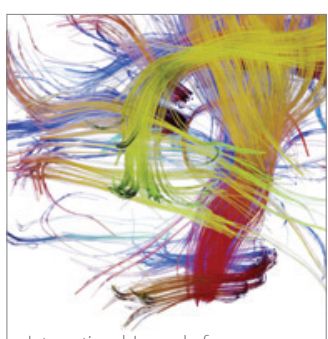

Brain Science

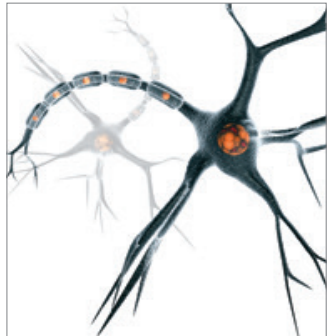

Neural Plasticity
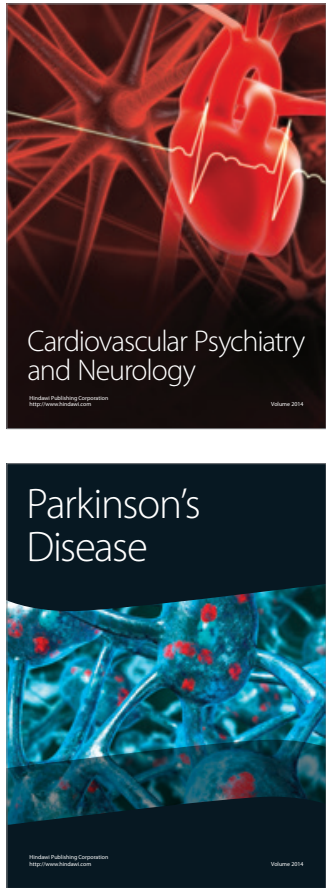